\title{
Post-colonoscopy colorectal cancer in Belgium: characteristics and influencing factors
}

\section{다)(우우}

\author{
Authors \\ Institutions \\ 1 Gastroenterology \& Hepatology, Antwerp University \\ Hospital, Edegem, Antwerp, Belgium \\ 2 Evolutionary Ecology Group, Department of Biology, \\ University of Antwerp, Antwerp, Belgium \\ 3 Belgian Cancer Registry, Brussels, Belgium \\ 4 Pathology, Antwerp University Hospital, Edegem, \\ Antwerp, Belgium \\ 5 Medical Sociology and Health Policy, University of \\ Antwerp, Antwerp, Belgium
}

Elisabeth Macken ${ }^{1}$, Stefan Van Dongen², Isabel De Brabander ${ }^{3}$, Sven Francque ${ }^{1}$, Ann Driessen ${ }^{4}$, Guido Van Hal ${ }^{5}$

submitted 30.5 .2018

accepted after revision 4.9.2018

Bibliography

DOI https://doi.org/10.1055/a-0751-2660 |

Endoscopy International Open 2019; 07: E717-E727

(c) Georg Thieme Verlag KG Stuttgart · New York eISSN 2196-9736

\section{Corresponding author}

Elisabeth Macken, MD, Gastroenterology \& Hepatology, Antwerp University Hospital, Wilrijkstraat 10, 2650

Edegem, Antwerp, Belgium

Fax: $+32-3-8214478$

elisabeth.macken@uza.be

\begin{abstract}
Background and study aims Post-colonoscopy colorectal cancer (PCCRC) is an important quality parameter of colonoscopy. Most studies have shown that the risk for colorectal cancer is reduced after an index colonoscopy for screening or diagnostic purposes with or without polypectomy. In this study, we aimed to quantify and describe PCCRC in Belgium, including the possible relationships with patient, physician, and colonoscopy characteristics.
\end{abstract}

Patients and methods Reimbursement data on colorectal related medical procedures from the Intermutualistic Agency (IMA-AIM) were linked with data on clinical and pathological staging of colorectal cancer (CRC) available at the Belgian Cancer Registry (BCR) over a period covering 9 years $(2002-2010)$.

Results In total, 63518 colorectal cancers were identified in 61616 patients between 2002 and 2010. We calculated a mean PCCRC rate of $7.6 \%$. PCCRC was significantly higher in older people and correlated significantly with polyp detection rate and the number of resections and procedures performed per year per physician. Conditional observed survival, given still alive 3 years since first colonoscopy, for PCCRC was worse than for CRC. Older patients and patients with invasive carcinomas had a worse outcome.

Conclusions Although no quality register exists in Belgium, we were able to demonstrate that PCCRC in Belgium is directly related to the experience of the physician performing the procedure. In the absence of a quality register, utilization of population-based data sources proved to be a valuable tool to identify quality parameters.

\section{Introduction}

Most studies have shown that the risk for colorectal cancer is reduced after screening colonoscopy and colonoscopy with polypectomy [1-4] and that the protective effect lasts for 10 years, because most cancers originate from polyps (adenoma - carcinoma sequence) [5]. A post-colonoscopy colorectal cancer (PCCRC) is a cancer detected following a negative screening colonoscopy, in which the cancer was hence not detected. Most PCCRCs probably represent missed lesions or incompletely resected lesions and may be a reason for quality concern $[6,7]$.
Some colon cancers may, however, show a different biology, may be very aggressive and grow faster. This study aimed to analyze the incidence of PCCRC in Belgium and to define the influencing factors.

\section{Patients and methods}

\section{Data sources}

For this study, data from the Belgian Cancer Registry (BCR) and the Intermutualistic Agency (IMA-AIM) were used. The BCR, a national population-based cancer registry, is legally authorized 
to collect all data on new cancer diagnoses. These data are provided by the oncological care programs and the laboratories for pathological anatomy. The IMA-AIM collects all reimbursement data of medical procedures, provided by the seven health insurance companies in Belgium. In Belgium, more than $99 \%$ of people are insured thanks to compulsory health insurance. All of these people are members of one of the seven health insurance organizations in Belgium and are included in the study. So more than $99 \%$ of colonoscopies are captured in this study.

\section{Study dataset}

For the current analysis, the BCR pooled and coded reimbursement data on specific procedures (listed in $>$ Table 1) from the IMA-AIM with colorectal cancer data, including information on clinical and pathological staging. This dataset comprised data collected between 1 January 2002 and 31 December 2010, apart from Wallonia and Brussels due to incomplete data between 2002 and 2004. Location and histology of the cancers were coded using the International Classification of Diseases for Oncology (ICD-O-3). Based on the CRC coding, the CRC site was classified into right-sided CRC (C 18.0 cecum, ileocecal valve; C 18.2 ascending colon; $C 19$ hepatic flexure), middle-sided CRC (C 18.4 transverse colon), left-sided CRC (C 18.5 splenic flexure; C 18.6 descending colon; $C 18.7$ sigmoid colon; $C$ 19 rectosigmoid junction, and $C 20$ rectum), and unspecified CRC location (C 18.8 overlapping lesion in colon and C 18.9 colon, unspecified).

All appendiceal, non-epithelial, neuroendocrine, and unspecified tumors were omitted ( $\triangleright$ Fig. 1 ).

By combining clinical and pathological TNM classification, stage was available for $80 \%$ of all colorectal cancer cases.
70510 CRC's between 01/01/2002 and 31/12/2010

$\Downarrow$ Omitting 6992 CRC's without colonoscopy

63518 CRC's in 61616 patients who underwent a colonoscopy between $01 / 01 / 2002$ and $31 / 12 / 2010$

Omitting all non 'adenocarcinomas and its variants'

57502 CRC's (adenocarcinoma and its variants) in 55920 patients with a colonoscopy

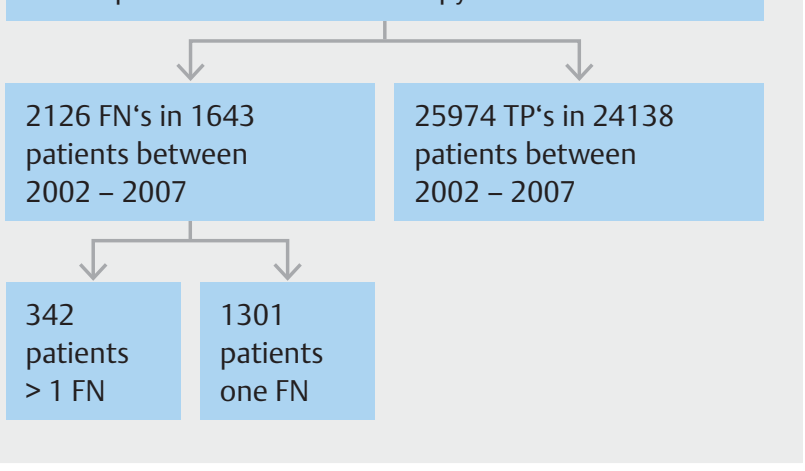

Fig. 1 Patient flow chart.

Information about in situ or invasive carcinomas (behavior / 2 and /3) was available for all patients.

In total, 1731 patients with more than one tumor were present. For 1170 patients, the incidence dates of tumors fell within

- Table 1 Examinations recorded and terminology.

\begin{tabular}{|c|c|c|}
\hline $\begin{array}{l}\text { Nomenclature code } \\
\text { as per IMA }\end{array}$ & Type of examination & Remarks \\
\hline $472452-472463$ & Rectosigmoidoscopy & \\
\hline $473130-473141$ & Left colonoscopy & Withdrawn 1 February 2013 \\
\hline $473174-473185$ & Total colonoscopy & $\begin{array}{l}\text { Examination refunded for a complete or incomplete } \\
\text { examination (until the hepatic flexure) }\end{array}$ \\
\hline $473955-473966$ & Additional number for polypectomy & $\begin{array}{l}\text { Can be added to endoscopic examination since } 1 \text { February } \\
2009\end{array}$ \\
\hline $473432-473443$ & Ileoscopy & \\
\hline $473756-473760$ & Ileoscopy with removal of tumor & \\
\hline $473211-473222$ & Resection of polyps & Cannot be added to endoscopy; refunded only once a year \\
\hline $472511-472522$ & Rectoscopy & \\
\hline $588011-588022$ & Pathologic examination & Charged by pathologist \\
\hline Full Colonoscopy & Total colonoscopy or ileoscopy (without resection) & \\
\hline Full Procedure & $\begin{array}{l}\text { Total colonoscopy or ileoscopy or polypectomy (with } \\
\text { or without resection) }\end{array}$ & \\
\hline Polypectomy & $\begin{array}{l}\text { Resection of polyps and additional number for } \\
\text { resections of polyps }\end{array}$ & \\
\hline
\end{tabular}


60 days and were considered to be synchronic tumors. Metachronous tumors developed in 590 patients.

The staging of the tumors was classified as follows: TONOMO; T1/T2N0M0; T3N0M0; T4N0M0; T1/2N1M0; T3/4N1M0, any TN2M0; anyT, anyN, M1. In all analyses, staging was treated as a continuous explanatory variable.

\section{Definitions}

We characterized colonoscopy as either false negative (FN) or true positive (TP) according to Morris et al. [8]. We took into account only full procedures (total colonoscopy or ileoscopy or polypectomy (resection polyp), > Table $\mathbf{1}$ ).

Cancer was defined as a post-colonoscopy colorectal cancer (PCCRC) if a FN colonoscopy preceded the detection or incidence date. Recording of a CRC may have been delayed after colonoscopy, therefore all colonoscopies performed within 6 months before the date of diagnosis were considered to be true positive colonoscopies. To take minor administrative deviations into account, all colonoscopies performed within 2 weeks after the date of diagnosis were also considered to be true positive colonoscopies. PCCRC was defined as a cancer found during colonoscopy between 6 and 36 (721 - 1080 days) months after a negative colonoscopy. We chose this window because we had a data set of only 10 years. This meant that, although we had data until 2010, the time period 2008-2010 could not be included for the estimation of PCCRC up to 36 months after a negative colonoscopy due to the time perspective of the method ( $\triangleright$ Fig. 1 ).

We calculated the PCCRC rate adapting the method described by Morris et al. [8]. In this method, the denominator is the number of colonoscopies in patients with colorectal cancer. The appearance of cancer over 3 years is the gold standard: the true positives plus the false negatives. The PCCRC rate is calculated as the number of false negative colonoscopies divided by the gold standard. We adapted this method, and calculated the PCCRC rate taking into account all false negative colonoscopies, and not only the first false negative colonoscopy as was described by Morris et al. ( Fig. 2). PCCRC is a characteristic of a colonoscopy, and one patient can have more than one PCCRC. For our calculations with respect to tumor characteristics, analyses were done at a patient level. By doing so, we were sure each patient was only counted once.

Recently, Rutter et al. published the WEO recommendations for the methodology that should be used to calculate PCCRC rate to ensure there is a consistent approach to calculating rates. We also calculated PCCRC using the WEO recommendations, where only one false negative colonoscopy (the closest) is included [9].

\section{Methodology}

For the calculation of PCCRC rates, all unique tumors were used because failing to detect a tumor during colonoscopy can be considered to be a tumor-specific event. For the survival analysis, however, survival after the diagnosis of the first tumor was analyzed. In the case of synchronous tumors, the most severe tumor characteristics were selected (invasive vs. in situ; and rank of staging) to be used in the analyses when correcting for tumor characteristics.

We calculated PCCRC rates according to different patient [age, gender], tumor [location, behavior], and colonoscopy

\section{Patient A}

2 colonoscopies: one 6 - 36 months before diagnosis (eg 04-2005) and one 0 - 6 months before diagnosis (eg 06-2007): 1 DC 2007 and 1 PCCRC for 2005

colonoscopy
04-2005
false negative

\section{Patient B}

3 colonoscopies: two 0 - 36 months before diagnosis (eg 04-2005 and 05-2006), and one 6 - 36 months before diagnosis (eg 06-2007): one PCCRC for 2005, one PCCRC for 2006 and one DC for 2007

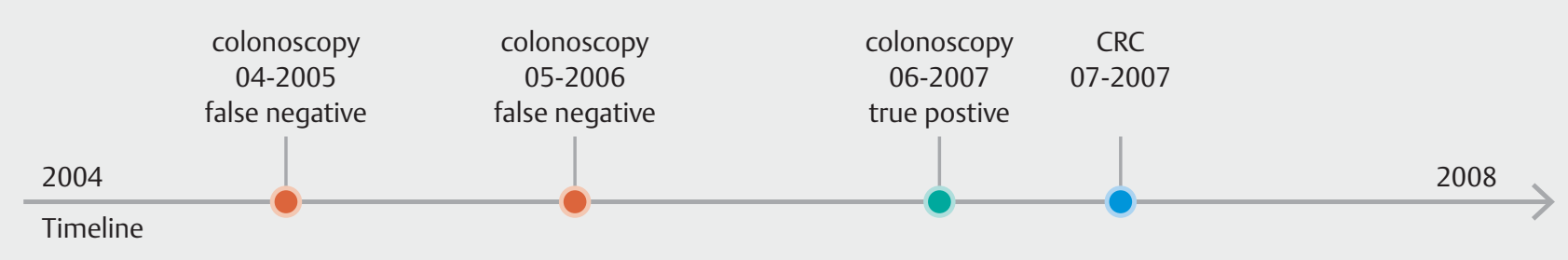

- Fig. 2 Calculation of post-colonoscopy colorectal cancer (PCCRC). 
[use of sedation (conscious sedation was defined as the use of midazolam and fentanyl administered by the endoscopist, and deep sedation as the use of propofol administered by the anesthesiologist), resection during colonoscopy, and physician speciality] characteristics and compared them statistically using both a univariate and multiple linear logistic regression. In the multiple linear logistic ANOVA model, all factors significant in the univariate analysis were included. We chose not to include all factors irrespective of their statistical significance to avoid fitting overly complex models with a high likelihood of multicollinearity problems and variance inflation. In addition, given the relatively high sample sizes in this study, effects that were not statistically significant were very likely to be unimportant and thus unlikely to have important effects in the multiple analyses if they had been included. The relationships between the stage score and the occurrence of PCCRC colonoscopies were analyzed using a logistic regression model.

Next, PCCRC rates were compared among groups of physicians with different polyp detection rates (PDR), number of resections performed per year and number of full procedures performed per year. We calculated PDR as all polypectomies divided by all full procedures. A full procedure was defined as a total colonoscopy or ileoscopy (with or without resection) or polypectomy ( $\downarrow$ Table $\mathbf{1})$. A polypectomy was defined as a resection of a polyp, not just a recording. A logistic ANOVA model was used to test for differences among these physician groups and pairwise comparisons were based on the MCB method (multiple comparisons with the best) [10]. This technique allowed us to identify groups of physicians with relatively high rates of PCCRC in order to make recommendations for minimal performances to reduce PCCRC rates.

Between-physician and between-hospital variation in PCCRC rates are presented as funnel graphs and tested for significance using a logistic ANOVA model.

Reference groups were defined as groups with the lowest a priori expected PCCRC (so the expected odds ratios are greater than 1).

A survival analysis was performed to estimate differences in survival between patients where the first diagnosed tumor was classified as an interval cancer/not interval cancer. The wellknown problem of lead time bias was avoided by calculating the survival times from the time of colonoscopy instead of time of cancer diagnosis. In addition to this problem of lead time bias, there is a second issue that requires an adaptation of a classic survival analysis because patients with or without PCCRC have different expected survival times due to the way PCCRC is defined. While all patients without PCCRC will be present in the dataset, even if they die immediately after the colonoscopy leading to the CRC diagnosis, patients with PCCRC must survive at least 6 and up to 36 months after colonoscopy to be available for analysis. For example, if a patient with a FN colonoscopy dies 1 year later for whatever reason and before the CRC is diagnosed, he/she will not end up in the dataset, while a patient with a TP at the same time point would be part of the analysis. This aspect thus artificially increases survival times of PCCRC patients (those who die early are missing from the dataset). To avoid this second source of bias, our survival analysis was performed conditionally and only based on patients still alive 3 years after the first colonoscopy. We performed a Cox proportional hazards analysis with PCCRC/no PCCRC as a factor. The hazard ratio was an estimate for a model without correcting for any covariates, as well as a model correcting for possible effects of age, sex, tumor type, and location, the presence of synchronous and metachronous tumors, and level of staging (as a continuous covariate). Last observation date was 7 January 2013; this was the last date of death in our database. A Kaplan - Meier survival curve was estimated.

\section{Ethics}

The transfer of personal data required for this study was approved by the Sector Committee of Social Security and Health on 22 October 2013. All data were coded.

\section{Results}

As we described in our article about the quality of colonoscopy in Belgium [11], 1027949 full colonoscopies were performed in Belgium in 994047 patients between 2002 and 2010.

\section{Characteristics of tumors and patients}

In Belgium, 63518 colorectal cancers were diagnosed from 1 January 2002 until 31 December 2010.

All non-epithelial (mesenchymal and lymphoid tumors) were omitted, as were appendiceal tumors, neuroendocrine and unclassified tumors, squamous cell and basaloid carcinomas (6016 tumors), leaving 57502 adenocarcinomas and its variants (code 8140, 8141, 8143, 8145, 8147, 8148, 8210, 8211, $8220,8221,8230,8244,8260,8261,8262,8263,8310$, $8320,8430,8481,8490,8510,8560,8574,8575,8576)$.

In total, 6992 colorectal carcinomas were diagnosed without (charged) colonoscopy.

The characteristics of tumors, patients, and their PCCRC rates are shown in T Table 2. Between 2002 and 2007, 1643 patients with 2126 false negative (FN) colonoscopies were identified, which were considered to be PCCRC ( $\triangleright$ Fig.1). Of this group of patients, 1301 patients had one FN colonoscopy, 256 patients had 2 FN colonoscopies, 52 patients had 3 FN colonoscopies, 23 patients had 4 FN colonoscopies, 5 patients had $5 \mathrm{FN}$ colonoscopies, 3 patients $6 \mathrm{FN}$ colonoscopies, 2 patients 7 FN colonoscopies, and 1 patient had 8 FN colonoscopies ( $\triangleright$ Fig. 1 ). The mean PCCRC rate among all cancers diagnosed within 36 months after all full procedures performed between 2002 and 2007 was $7.6 \%$, and was somewhat lower (i.e., PCCRC $=5.1 \%$ ) when synchronous tumors occurred ( $\vee$ Table 2 ). PCCRC rates differed significantly between different patient, tumor, and colonoscopy characteristics (see - Table 2 for details and > Fig. 3 for a graphical summary).

PCCRC was found more frequently in older people (more than 74 years old), but did not differ between males and females ( $>$ Table 2 ; $>$ Fig. 3). PCCRC occurred more frequently for tumors in the middle and right hemicolon compared to the left hemicolon and for tumors of unknown location and overlapping areas. PCCRC was higher for in situ tumors compared to invasive tumors ( $\triangleright$ Table 2 ; $\triangleright$ Fig.3). With respect to the 
- Table 2 Overview of PCCRC rates after 6-36 months. Comparisons among patient, tumor, and colonoscopy characteristics are provided and tested for their statistical significance.

\begin{tabular}{|c|c|c|c|c|c|c|c|c|}
\hline & & \multirow{2}{*}{$\begin{array}{l}\text { Numbers and } \\
\text { PCCRC (\%) }\end{array}$} & \multicolumn{3}{|l|}{ Univariate } & \multicolumn{3}{|l|}{ Multiple } \\
\hline & & & Odds ratio & $95 \% \mathrm{Cl}$ & $P$ value & Odds ratio & $95 \% \mathrm{Cl}$ & $P$ value \\
\hline \multirow[t]{2}{*}{ All } & FN & $2126(7.6)$ & \multirow[t]{2}{*}{-} & \multirow[t]{2}{*}{-} & \multirow[t]{2}{*}{-} & \multirow[t]{2}{*}{-} & \multirow[t]{2}{*}{-} & \multirow[t]{2}{*}{-} \\
\hline & $\mathrm{FN}+\mathrm{TP}$ & 28100 & & & & & & \\
\hline \multirow{2}{*}{$\begin{array}{l}\text { All (without multi- } \\
\text { ple tumors) }\end{array}$} & $\mathrm{FN}$ & $2070(7.6)$ & \multirow[t]{2}{*}{-} & \multirow[t]{2}{*}{-} & \multirow[t]{2}{*}{-} & \multirow[t]{2}{*}{-} & \multirow[t]{2}{*}{-} & \multirow[t]{2}{*}{-} \\
\hline & $\mathrm{FN}+\mathrm{TP}$ & 27057 & & & & & & \\
\hline \multirow{2}{*}{$\begin{array}{l}\text { All (only double } \\
\text { tumors) }\end{array}$} & $\mathrm{FN}$ & $56(5.4)$ & - & - & - & - & - & - \\
\hline & $\mathrm{FN}+\mathrm{TP}$ & 1043 & & & & & & \\
\hline Location & & & \multicolumn{3}{|c|}{ Overall test: $x^{2}=143 ;$ d.f. $=4 ; P<0.0001$} & \multicolumn{3}{|c|}{$X^{2}=141 ;$ d.f. $=4 ; P<0.0001$} \\
\hline \multirow{2}{*}{$\begin{array}{l}\text { Sigmoid colon/ } \\
\text { rectosigmoid } \\
\text { junction }\end{array}$} & $\mathrm{FN}$ & $519(5.6)$ & \multirow[t]{2}{*}{0.83} & \multirow[t]{2}{*}{$0.73-0.94$} & \multirow[t]{2}{*}{0.004} & \multirow[t]{2}{*}{0.86} & $0.75-0.98$ & 0.007 \\
\hline & $\mathrm{FN}+\mathrm{TP}$ & 9332 & & & & & & \\
\hline - Left & FN & 459 (6.6) & Reference & - & - & Reference & - & - \\
\hline & $\mathrm{FN}+\mathrm{TP}$ & 6911 & & & & & & \\
\hline - Middle & FN & $120(11.1)$ & 1.75 & $1.41-2.16$ & $<0.0001$ & 1.79 & $1.44-2.21$ & $<0.0001$ \\
\hline & $\mathrm{FN}+\mathrm{TP}$ & 1082 & & & & & & \\
\hline - Right & FN & 738 (9.8) & 1.53 & $1.36-1.73$ & $<0.0001$ & 1.61 & $1.42-1.82$ & $<0.0001$ \\
\hline & $\mathrm{FN}+\mathrm{TP}$ & 7513 & & & & & & \\
\hline - Unknown/over- & FN & $290(8.9)$ & 1.37 & $1.18-1.60$ & $<0.0001$ & 1.34 & $1.14-1.56$ & $<0.0001$ \\
\hline lapping & $\mathrm{FN}+\mathrm{TP}$ & 3262 & & & & & & \\
\hline Tumor behavior & & & & & & & & \\
\hline - In situ & $\mathrm{FN}$ & 341 (13.3) & 2.04 & $1.80-2.31$ & $<0.0001$ & 2.17 & $1.91-2.45$ & $<0.0001$ \\
\hline & $\mathrm{FN}+\mathrm{TP}$ & 2224 & & & & & & \\
\hline - Invasive & FN & $1785(7.0)$ & Reference & - & - & Reference & - & - \\
\hline & $F N+T P$ & 23750 & & & & & & \\
\hline Gender & & & & & & & & \\
\hline - Male & FN & $1201(7.5)$ & Reference & - & - & Reference & - & - \\
\hline & $\mathrm{FN}+\mathrm{TP}$ & 15990 & & & & & & \\
\hline - Female & FN & $925(7.6)$ & 1.02 & $0.93-1.11$ & 0.69 & 0.96 & $0.88-1.05$ & 0.37 \\
\hline & $\mathrm{FN}+\mathrm{TP}$ & 12110 & & & & & & \\
\hline Deep sedation & & & & & & & & \\
\hline . No & $\mathrm{FN}$ & $1673(8.2)$ & 1.44 & $1.29-1.60$ & $<0.0001$ & 1.50 & $1.35-1.65$ & $<0.0001$ \\
\hline & $\mathrm{FN}+\mathrm{TP}$ & 18700 & & & & & & \\
\hline - Yes & FN & $453(5.9)$ & Reference & - & - & Reference & - & - \\
\hline & $\mathrm{FN}+\mathrm{TP}$ & 7274 & & & & & & \\
\hline Resection & & & & & & & & \\
\hline . No & $\mathrm{FN}$ & $1214(7.3)$ & Reference & - & - & Reference & - & - \\
\hline & $\mathrm{FN}+\mathrm{TP}$ & 15497 & & & & & & \\
\hline - Yes & $\mathrm{FN}$ & $912(8.6)$ & 1.10 & $1.01-1.21$ & 0.02 & 1.10 & $1.00-1.20$ & 0.06 \\
\hline & $\mathrm{FN}+\mathrm{TP}$ & 10477 & & & & & & \\
\hline
\end{tabular}


- Table 2 (Continuation)

\begin{tabular}{|c|c|c|c|c|c|c|c|c|}
\hline & & \multirow{2}{*}{$\begin{array}{l}\text { Numbers and } \\
\text { PCCRC (\%) }\end{array}$} & \multicolumn{3}{|l|}{ Univariate } & \multicolumn{3}{|l|}{ Multiple } \\
\hline & & & Odds ratio & $95 \% \mathrm{Cl}$ & $P$ value & Odds ratio & $95 \% \mathrm{Cl}$ & $P$ value \\
\hline Speciality & & & \multicolumn{3}{|c|}{ Overall test: $x^{2}=36.4 ;$ d.f. $=2 ; P<0.0001$} & \multicolumn{3}{|c|}{$X^{2}=31.5 ;$ d.f. $=2 ; P<0.0001$} \\
\hline \multirow[t]{2}{*}{ - Surgeon } & FN & $27(10.8)$ & \multirow[t]{2}{*}{2.04} & \multirow[t]{2}{*}{$1.34-3.00$} & \multirow[t]{2}{*}{0.0005} & \multirow[t]{2}{*}{1.95} & \multirow[t]{2}{*}{$1.28-2.88$} & \multirow[t]{2}{*}{0.001} \\
\hline & $F N+T P$ & 223 & & & & & & \\
\hline \multirow[t]{2}{*}{. Intern } & FN & $550(7.3)$ & \multirow[t]{2}{*}{1.33} & \multirow[t]{2}{*}{$1.20-1.48$} & \multirow[t]{2}{*}{$<0.0001$} & \multirow[t]{2}{*}{1.31} & \multirow[t]{2}{*}{$1.18-1.45$} & \multirow[t]{2}{*}{$<0.0001$} \\
\hline & $F N+T P$ & 6960 & & & & & & \\
\hline \multirow{2}{*}{$\begin{array}{l}\text { - Gastroentero- } \\
\text { logist }\end{array}$} & FN & $1216(5.6)$ & \multirow[t]{2}{*}{ Reference } & \multirow[t]{2}{*}{-} & \multirow[t]{2}{*}{-} & \multirow[t]{2}{*}{ Reference } & \multirow[t]{2}{*}{-} & \multirow[t]{2}{*}{-} \\
\hline & $F N+T P$ & 20527 & & & & & & \\
\hline Age & & & \multicolumn{3}{|c|}{ Overall test: $x^{2}=34.1 ;$ d.f. $=4 ; P<0.0001$} & \multicolumn{3}{|c|}{$X^{2}=18.0 ;$ d.f. $=4 ; P<0.0001$} \\
\hline \multirow[t]{2}{*}{. $<55$} & FN & $188(6.9)$ & \multirow[t]{2}{*}{ Reference } & \multirow[t]{2}{*}{-} & \multirow[t]{2}{*}{-} & \multirow[t]{2}{*}{ Reference } & \multirow[t]{2}{*}{-} & \multirow[t]{2}{*}{-} \\
\hline & $F N+T P$ & 2534 & & & & & & \\
\hline - $55-64$ & FN & $347(6.8)$ & 0.99 & $0.82-1.19$ & 0.91 & 0.99 & $0.82-1.19$ & 0.91 \\
\hline & $F N+T P$ & 4726 & & & & & & \\
\hline - $65-74$ & FN & $607(6.8)$ & 0.99 & $0.83-1.16$ & 0.86 & 0.95 & $0.80-1.13$ & 0.53 \\
\hline & $\mathrm{FN}+\mathrm{TP}$ & 8365 & & & & & & \\
\hline - $75-84$ & FN & $785(8.6)$ & 1.27 & $1.07-1.50$ & 0.005 & 1.17 & $0.99-1.38$ & 0.06 \\
\hline & $F N+T P$ & 8363 & & & & & & \\
\hline - 85 and older & FN & $199(9.1)$ & 1.35 & $1.10-1.60$ & 0.004 & 1.18 & $0.96-1.46$ & 0.12 \\
\hline & $\mathrm{FN}+\mathrm{TP}$ & 1986 & & & & & & \\
\hline
\end{tabular}

FN: false negatives, TP: true positives.

The reference group was estimated as the intercept of the statistical model.

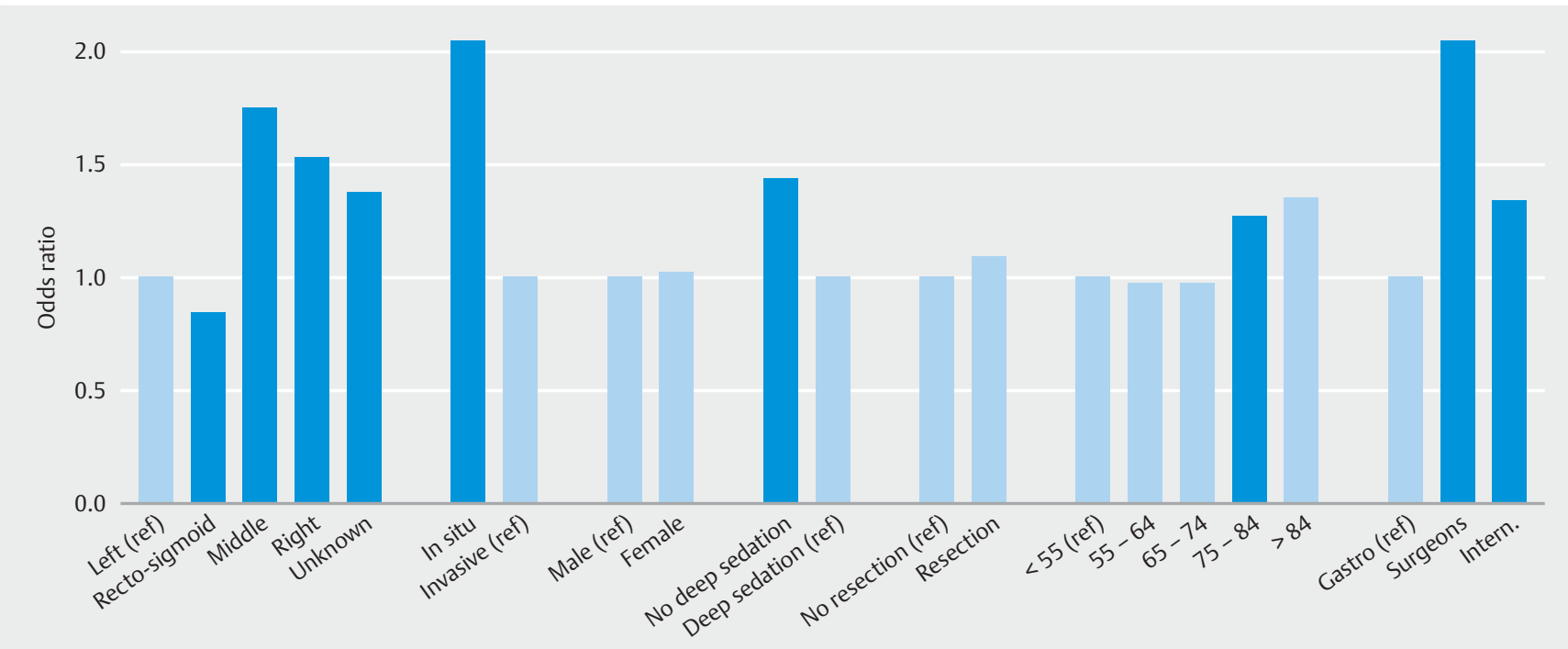

- Fig. 3 Bar chart of PCCRC rate according to patient, procedure, and tumor characteristics. Black bars indicate groups that differ significantly from the reference groups. Reference groups are defined as groups with the lowest a priori expected PCCRC (so the expected odds ratios are greater than 1). 
characteristics of the colonoscopy, PCCRC rate was lower when colonoscopies were performed by a gastroenterologist, when deep sedation was used, but did not differ when a resection was or was not performed ( Table 2 ; $>$ Fig. 3 ). PCCRC rates decreased significantly with the stage score $\left(x^{2}=103\right.$, d.f. $=1$, $P<0.0001$; slope $=-0.06$ (SE=0.006).

PCCRC rate, calculated following the WEO recommendations, was $7.4 \%$.

\section{Physician characteristics}

PCCRC was more frequently associated with physicians with a low polyp detection rate (PDR, defined as all polypectomies divided by all full procedures) (PDR less than $20 \%$ vs. $20 \%$ or higher, $X^{2}=64.1$, d.f. $=8, P<0.0001$, $>$ Fig.4, left panel), with physicians performing few resections a year (less than 80 resections a year vs. 80 or more, $X^{2}=62.3$, d.f. $=10, P<0.0001$, - Fig.4, middle panel), and with low-volume physicians (low volume calculated as performing fewer than 225 full procedures per year, $X^{2}=41.5$, d.f. $=9, P<0.0001$, $>$ Fig. 4 , right panel). There was a more than 10 -fold variation in PCCRC rates between individual physicians in Belgium in the study period ( $\triangleright$ Fig. 5, left panel). The funnel graph showed that $20 \%$ of the physicians fell outside the $95 \%$ confidence bands and $7 \%$ outside the $99 \%$ confidence bands, which is in agreement with the observed statistically significant variation ( $\mathbf{F i g}$. 5). There was also highly significant inter-hospital variation, where, according to the funnel graph, $30 \%$ and $14 \%$ of the hospitals fell outside the $95 \%$ and $99 \%$ prediction bands, respectively, again confirming the statistically significant variation ( $>$ Fig.5, right panel).

\section{Survival analysis}

Conditional survival - being alive 3 years after colonoscopy was significantly worse for patients with PCCRC, both with and without correction for different covariates ( $>$ Table 3 ). In spite of the fact that several of the variables were added to the Cox proportional hazards model to obtain an adjusted estimate for the effect of PCCRC, the hazard ratios were very similar in magnitude ( $\triangleright$ Table 3 ). In patients without PCCRC, more than $50 \%$ were still alive after 8 years, such that median survival could not be determined. Comparisons at higher quantiles showed that, in the PCCRC group, $80 \%$ of the patients survived for 1.6 years ( $95 \% \mathrm{Cl}: 1.2-2.0)$ while this was 2.8 years $(95 \% \mathrm{Cl}: 2.6-$ 2.9) for patients without PCCRC. For $60 \%$ survival, this was

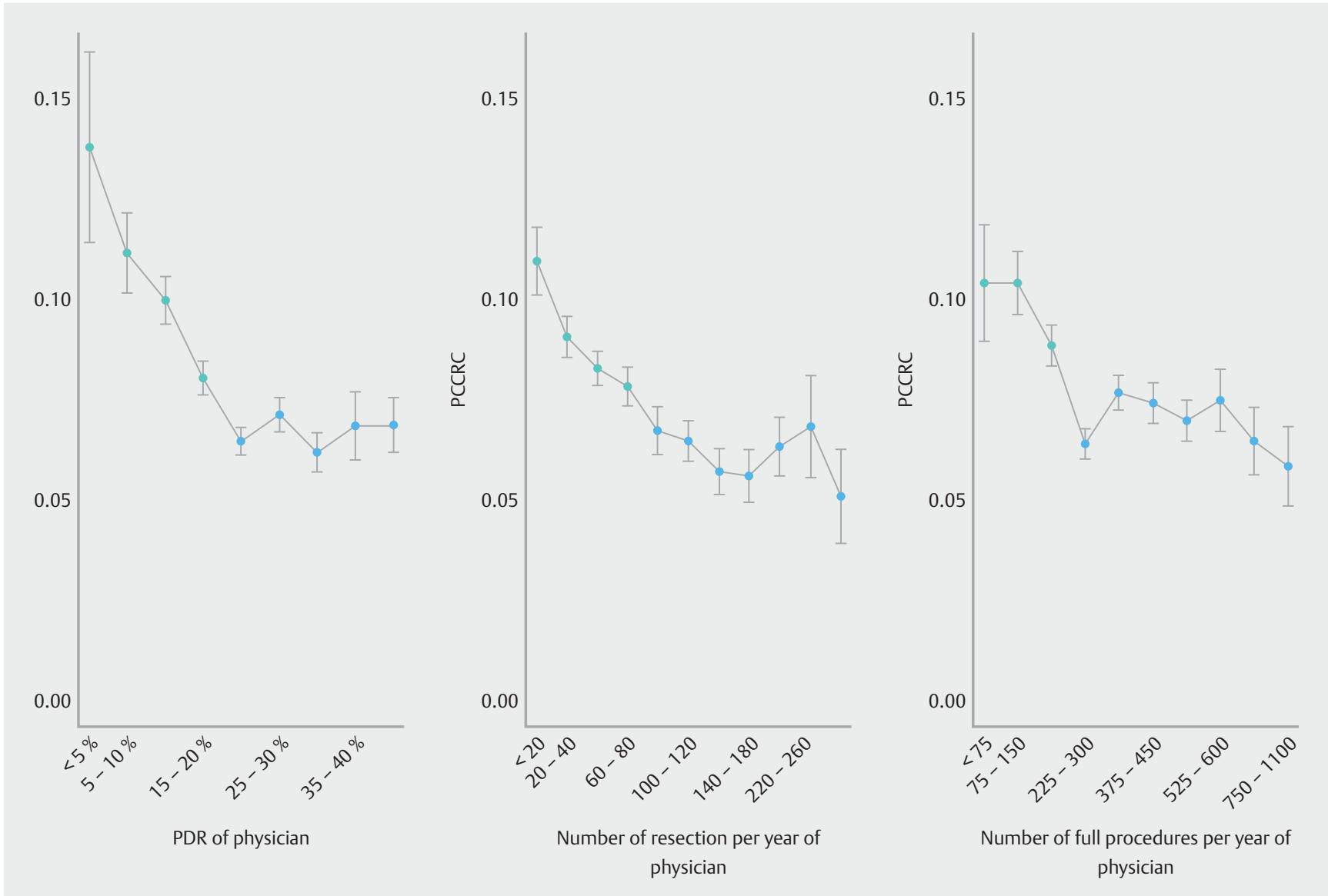

- Fig. 4 Differences in PCCRC rates among physicians with: left panel: different polyp detection rates (PDR); middle panel: different numbers of resections performed on a yearly basis; right panel: different numbers of full procedures performed on a yearly basis. Mean PCCRC (SE) rates indicated in gray differ significantly from those indicated in black, supporting a significantly higher PCCRC rate for physicians with PDR below 20 \% (left panel), with less than 80 resections performed per year (middle panel), and with less than 225 full procedures performed per year (right panel). 
- Table 3 Hazard ratios of the Cox proportional hazard model comparing conditional observed survival of patients with or without PCCRC, and correcting for sex, tumor behavior (in situ vs. invasive), tumor location (right and middle vs. others), age, presence of multiple tumors (synchronous and metachronous) and level of staging (continuous explanatory variable). The uncorrected hazard ratio for interval cancer is also provided.

\begin{tabular}{|c|c|c|c|}
\hline Factor & Hazard ratio & $95 \%$ C. I. & $P$ value \\
\hline \multicolumn{4}{|l|}{ Sex } \\
\hline - Male & Reference & & \\
\hline - Female & 0.68 & $0.64-0.73$ & $<0.0001$ \\
\hline \multicolumn{4}{|l|}{ Tumor type } \\
\hline - In situ & Reference & & \\
\hline - Invasive & 1.26 & $1.07-1.47$ & 0.0048 \\
\hline \multicolumn{4}{|l|}{ Tumor location } \\
\hline - Others & Reference & & \\
\hline - Right/middle & 1.14 & $1.06-1.23$ & 0.0003 \\
\hline \multicolumn{4}{|l|}{ Age } \\
\hline . $<45$ years & Reference & & \\
\hline . $45-54$ years & 1.04 & $0.76-1.55$ & 0.84 \\
\hline . 55-64 years & 1.72 & $1.19-2.47$ & 0.0042 \\
\hline . $65-74$ years & 2.57 & $1.73-3.67$ & $<0.0001$ \\
\hline . $75-84$ years & 5.12 & $3.59-7.32$ & $<0.0001$ \\
\hline . $>84$ years & 10.5 & $7.23-15.2$ & $<0.0001$ \\
\hline \multicolumn{4}{|c|}{ Multiple (synchronous) } \\
\hline - No & Reference & & \\
\hline - Yes & 1.10 & $0.87-1.39$ & 0.42 \\
\hline \multicolumn{4}{|c|}{ Multiple (metachronous) } \\
\hline - No & Reference & & \\
\hline - Yes & 1.47 & $1.18-1.84$ & $<0.0001$ \\
\hline Staging & 1.07 & $1.06-1.08$ & $<0.0001$ \\
\hline \multicolumn{4}{|l|}{ Interval cancer } \\
\hline \multicolumn{4}{|l|}{ - Corrected } \\
\hline - No & Reference & & \\
\hline - Yes & 1.35 & $1.18-1.53$ & $<0.0001$ \\
\hline \multicolumn{4}{|l|}{ - Uncorrected } \\
\hline - No & Reference & & \\
\hline - Yes & 1.38 & $1.22-1.57$ & $<0.0001$ \\
\hline
\end{tabular}



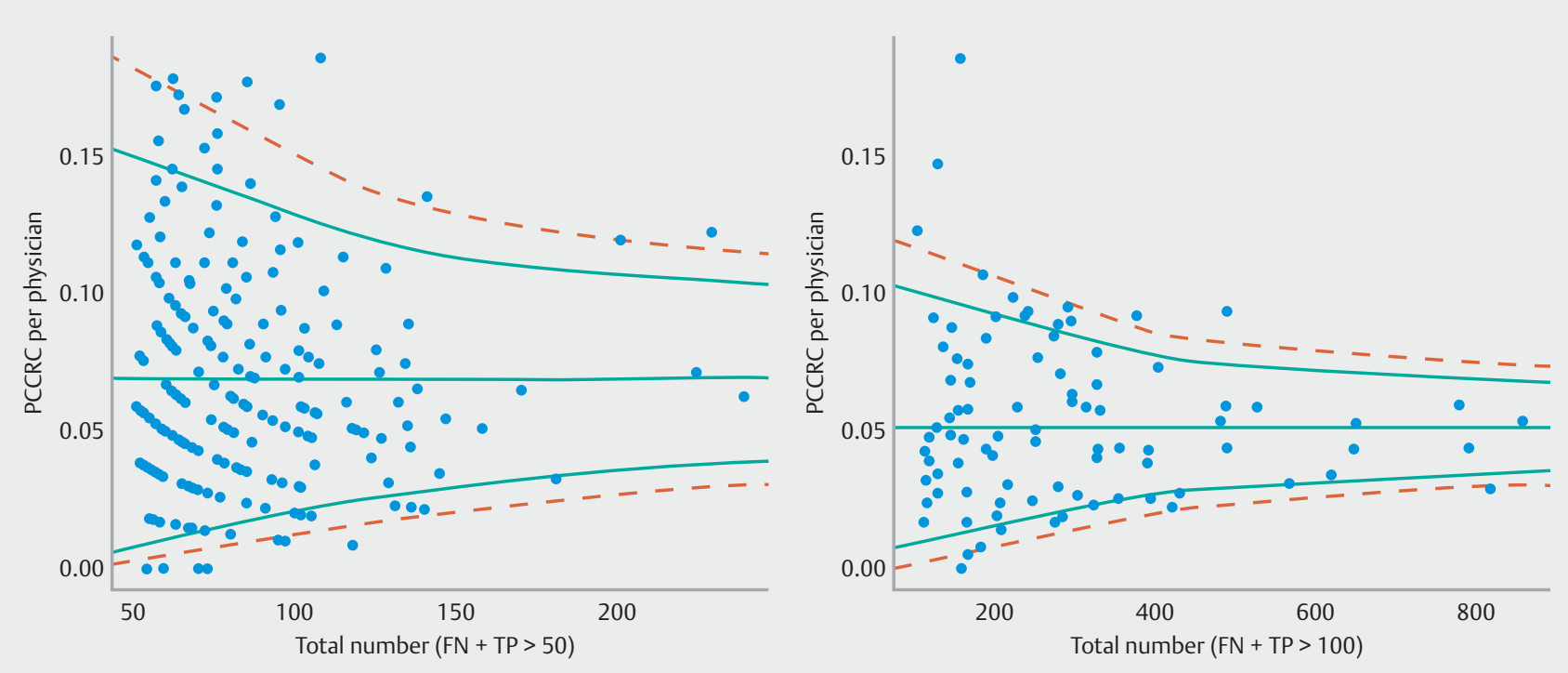

- Fig. 5 Funnel graph of: left panel: between-physician variation in PCCRC rates for physicians with more than 50 colonoscopies $(T P+F N)\left(X^{2}=\right.$ 476, degrees of freedom $=215, P<0.0001)$; right panel: between-hospital variation in PCCRC rates for hospitals with more than 100 colonoscopies $(T P+F N)\left(X^{2}=288\right.$, degrees of freedom $\left.=91, P<0.0001\right)$. Solid and dashed lines reflect $95 \%$ and $99 \%$ prediction bands, respectively. The horizontal line represents the average PCCRC rate across all physicians (left) or hospitals (right).

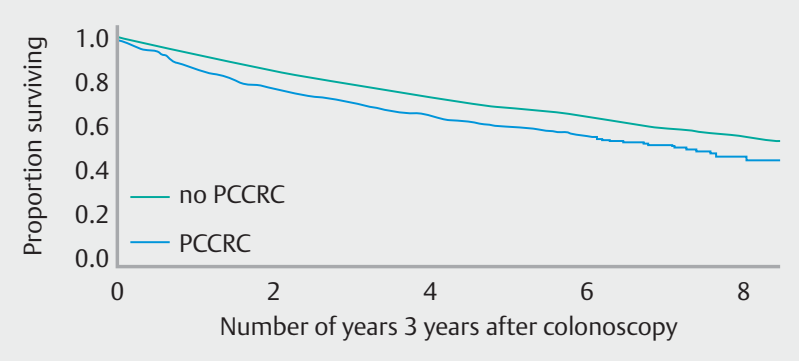

- Fig. 6 Conditional survival analysis (Kaplan - Meier curve uncorrected for other covariates ( $\triangleright$ Table 3$)$ ) for all patients still alive 3 years after date of first colonoscopy (year 0 on $x$ axis).

4.7 years $(95 \% \mathrm{Cl}: 4.0-6.0)$ for the PCCRC group and 6.7 years (95\%Cl: 6.5-7.2) for patients without PCCRC ( $\triangleright$ Fig. 6).

\section{Discussion}

In this retrospective study, we analyzed PCCRC rates in Belgium between 2002 and 2010 and their relationship to several characteristics of patients, tumors, and physicians.

The mean PCCRC rate in Belgium was $7.6 \%$. In other studies, rates from 12.1\% in England [12] to 2.7\% in Denmark [13], and $7.2 \%$ in the United States [14] have been observed. Thus, our estimates can be considered to be intermediate within this range. Differences in methodology used to calculate PCCRC rate, with different time frames and inclusion or exclusion criteria, have been invoked to explain these variations [8]. These different methods used different time frames and different inclusion or exclusion criteria.
We based our method on Morris et al. [8] but adapted their method. A standardized and uniform method to calculate PCCRC has recently been described by Rutter et al. (WEO consensus) [9]. In that method, in contrast to the method we used, only one (the closest) false negative colonoscopy was included, and all further false negative tests were reclassified as true negative tests. The PCCRC rate calculated using this WEO recommendation was $7.4 \%$.

\section{Characteristics of patients and tumor}

Higher PCCRC rates with older age and on the right side of the colon as observed by us were also described in other studies $[12,14-16]$. However, we did not find higher PCCRC rates in women as was described by Cheung et al. [12].

The higher PCCRC rate in the right side of the colon can be because right-sided lesions are more frequently serrated lesions, which are more difficult to detect and remove completely [17]. Moreover, bowel preparation is more likely to be inadequate in the right hemicolon.

The histology of CRC and PCCRC was not analyzed in most studies, although it is recommended by the WEO to omit all tumors for which colonoscopy is not considered the "gold standard" for the diagnosis (WEO CONSENSUS [9]). We excluded all non-epithelial tumors, non-specified carcinomas and neuroendocrine tumors, omitting 6016 tumors out of 63518.

Significantly more in situ tumors were found in the PCCRC group. This in contrast to other studies [18], where a higher likelihood of stage IV disease was found. 


\section{Characteristics of colonoscopy}

While we found a significantly lower PCCRC rate with the use of deep sedation (consistent with the observation in Belgium that more polyps are resected using deep sedation [11]), this is contradictory to the lower adenoma detection rate under deep sedation found by others [19]. Conscious sedation could limit the cecal intubation rate in technically more difficult colonoscopies. However, turning of the patients in conscious sedation could lead to better visualization of the mucosa $[1,20]$. In Belgium, most procedures are performed under deep sedation. However, turning of patients under deep sedation is dependent on the practice of the anesthesiologist in the hospital. Further investigation will be necessary to clarify these results.

In our study, no differences in PCCRC rates occurred when a polypectomy was or was not performed during the colonoscopy. This contradicts other results where a doubling of the risk of PCCRC has been described in the presence of a polypectomy [3, 14]. We hypothesize that most PCCRCs in Belgium should be considered missed lesions. As we demonstrated previously, intervals between colonoscopies in Belgium are shorter than suggested by the guidelines [11]. This implies that the vast majority of remnants of partially resected polyps are probably detected in a timely manner and removed. However, we have no information about the medical background of the patients, so we could not exclude patients with inflammatory bowel disease or hereditary nonpolyposis colorectal cancer (HNPCC). This may explain why so many procedures were performed in some patients.

\section{Characteristics of the endoscopist}

We could demonstrate that PCCRC in Belgium during our study period was dependent on the volume load (of procedures and polypectomies) performed by the physician. Although some studies did not demonstrate a relationship with procedure volume [16], this was countered by others [12] where PCCRC indeed appeared to be associated with lower volume endoscopists. We were able to demonstrate that there appears to be a threshold in our study in Belgium of a minimum of 225 full procedures per year to minimize PCCRC ( $\triangleright$ Fig. 4 , right panel). The recommended minimum number of procedures differs between guidelines (European Commission, 300 procedures; National Health Service of the UK (NHS) Bowel Cancer Screening Programme (BCSP), 150 screening procedures [21]). However, BCSP colonoscopies only account for $10 \%$ of colonoscopies performed in England, so for most colonoscopists, BCSP work is only a fraction of their practice.

In our study, the PCCRC rate did not diminish with higher colonoscopy volumes ( $\mathbf{F i g . 5}$ ). Also, we demonstrated that a minimum of 80 resections a year is necessary to minimize PCCRC ( $\triangleright$ Fig. 4, middle panel). Furthermore, a PDR of a minimum 20-25\% seems necessary to minimize PCCRC, as was demonstrated in > Fig. 4 (left panel).

PCCRC was thus highly significantly related to some physician characteristics, such as the number of procedures and polypectomies performed by an endoscopist and the PDR. This figure does not take into account the lifetime experience and overall competence of physicians that are also important parameters that are not appreciated in the overall numbers. However, these endoscopist characteristics could be used as surrogate quality parameters [16].

\section{Survival analysis}

In 2016, an analysis of the percentage lost to follow-up was calculated as $2.01 \%$ for patients with colorectal tumors diagnosed between 2004 and 2014. We demonstrated that conditional survival for PCCRC was worse than for CRC. This outcome was also reported by Govindarajan et al. [18] who found that PCCRCs were associated with a significantly worse oncological outcome. Most other studies, however, showed no difference in survival between individuals with PCCRC and controls $[6,13$, 22,23 ]. However, these studies did not calculate survival conditional on patients being alive 3 years after colonoscopy. It is crucial, however, to use such a conditional survival analysis to avoid bias by requiring patients with PCCRC to survive at least 6 months and up to 36 months to be available for analysis. This artificially increases survival times of PCCRC patients and can be the reason that better or equal survival times are reported in other studies. This effect can indeed be clearly seen in Fig. 2 of Samadder et al. [6] where the survival of PCCRC patients remains at a level of $100 \%$ for the time frame in which false negative colonoscopies can occur. This thus artificially increases survival of PCCRC patients and biases the survival analyses, a problem we have solved by using a conditional survival analysis. The hazard ratio of our survival analysis was also corrected for stage, age, type of tumor, localization of the tumor, and sex. Uncorrected survival analysis showed an even stronger effect of PCCRC. The hazard of dying from PCCRC increased by $35 \%$ compared to the CRC group ( $\triangleright$ Table 3 ).

Older patients and patients with invasive carcinomas also had a worse outcome. Worse survival of right-sided colorectal cancer is probably due to the older age of patients with rightsided colorectal cancer.

The strength of our study is that it is the first review that comprises information about all colonoscopies performed in Belgium during a 9-year follow-up period. The limitations are that some quality parameters are missing or incomplete.

In conclusion, the PCCRC rate in Belgium decreased in the first 2 years and remained stable thereafter at $7.6 \%$ in the period 2002 -2007. PCCRC was strongly related to age, right-sided CRC, use of deep sedation, and highly significantly related to some physician characteristics, such as the number of procedures and polypectomies performed by an endoscopist, and the PDR.

Survival of patients with PCCRC was worse than for patients with $C R C$, stressing the importance of a further reduction in PCCRC.

Although PCCRC rate and other quality parameters are not routinely measured at endoscopy units in Belgium, we demonstrated that the number of procedures and polypectomies performed by an endoscopist and the PDR could be some of the criteria used as surrogate quality parameters. The number of procedures, however, depends on the lifetime numbers and prior level of competence of endoscopists, but we did not have 
any information about their age or competence. But just as Rex and Ponugoti recommended using an overall adenoma detection rate $(A D R)$ rather than screening-only $A D R$ to simplify ADR measurement, to increase the number of examinations and eliminate gaming by changing the colonoscopy indication [24], systematic population data collection could prove a valuable tool to provide a colonoscopy quality bundle that could be validated against outcomes such as post-colonoscopy colorectal cancer.

These parameters can easily be recorded from reimbursement data, whereas the recording of other quality parameters, such as cecal intubation rate and withdrawal time, is dependent on the engagement of the endoscopist, and is susceptible to cheating as no electronic report or photographic evidence is required in Belgium. In this way, we think that systematic data collection from the population can provide us with parameters that can be used to compose a useful quality bundle. If we have access to the pathology of the resected polyps, we will even be able to calculate the ADR for the whole society and for each physician. These parameters, although blunt indicators, can be used in the first instance (in the absence of or awaiting a national colonoscopy register) to assess performance by measuring true patient outcome, and PCCRC rate (by calculating the amount of colonoscopies, the interval between colonoscopies, PDR, and ADR).

\section{Competing interests}

None

\section{References}

[1] Winawer S], Zauber AG, Ho MN et al. Prevention of colorectal cancer by colonoscopic polypectomy. The National Polyp Study Workgroup. NEJM 1993; 329: 1977-1981

[2] Brenner $\mathrm{H}$, Chang-Claude J, Seiler $\mathrm{CM}$ et al. Protection from colorectal cancer after colonoscopy: a population-based, case-control study. Ann Intern Med 2011; 154: 22-30

[3] Nishihara R, Wu K, Lochhead P et al. Long-term colorectal-cancer incidence and mortality after lower endoscopy. NEJM 2013; 369: $1095-1105$

[4] Pan J, Xin L, Ma YF et al. Colonoscopy reduces colorectal cancer incidence and mortality in patients with non-malignant findings: a metaanalysis. Am J Gastroenterol 2016; 111: 355-365

[5] Zauber AG, Winawer SJ, O'Brien M] et al. Colonoscopic polypectomy and long-term prevention of colorectal-cancer deaths. NEJM 2012; 366: 687-696

[6] Samadder N], Curtin K, Tuohy TM et al. Characteristics of missed or interval colorectal cancer and patient survival: a population-based study. Gastroenterology 2014; 146: 950 -960
[7] Robertson DJ, Lieverman DA, Winawer SJ et al. Colorectal cancers soon after colonoscopy: a pooled multicohort analysis. Gut 2014; 63 : 949-956

[8] Morris EJ, Rutter MD, Finan PJ et al. Post-colonoscopy colorectal cancer (PCCRC) rates vary considerably depending on the method used to calculated them: a retrospective observational population-based study of PCCRC in the English National Health Service. Gut 2015; 64: $1248-1256$

[9] Rutter MC, Beintaris I, Valori R et al. World Endoscopy Organization Consensus Statements on Post-Colonoscopy and Post-Imaging Colorectal Cancer. Gastroenterology 2018; 155: 909-925.e3

[10] Hsu J. Stepwise multiple comparisons with the best. J Stat Plan Interf 1992; 33: $197-204$

[11] Macken E, Van Dongen S, Francque S et al. Parameters influencing the quality of colonoscopy in Belgium: a critical evaluation. Acta Gastroenterol Belg 2018; 81: 29-38

[12] Cheung D, Evison F, Patel P et al. Factors associated with colorectal cancer occurrence after colonoscopy that did not diagnose colorectal cancer. Gastrointest Endosc 2016; 84: 287-295

[13] Erichsen R, Baron JA, Stoffel EM et al. Characteristics and survival of interval and sporadic colorectal cancer patients: a nationwide population-based cohort study. Am J Gastroenterol 2013; 108: $1332-1340$

[14] Cooper GS, Xu F, Barnholts Sloan JS et al. Prevalence and predictors of interval colorectal cancers in medicare beneficiaries. Cancer 2012; 118: $3044-3052$

[15] Bressler B, Paszat LF, Chen Z et al. Rates of new or missed colorectal cancers after colonoscopy and their risk factors: a population-based analysis. Gastroenterology 2007; 132: 96-102

[16] Baxter NN, Sutradhar E, Forbes SS et al. Analysis of administrative data finds endoscopist quality measures associated with postcolonoscopy colorectal cancer. Gastroenterology 2011; 140: 65-72

[17] Tadros M, Anderson JC. Serrated polyps: clinical implications and future directions. Curr Gastroenterol Rep 2013; 15: 342

[18] Govindarajan A, Rabeneck L, Yun L et al. Population-based assessment of the outcomes in patients with postcolonoscopy colorectal cancers. Gut 2016; 65: 971 - 976

[19] Nakshabendi R, Berry AC, Munoz JC et al. Choice of sedation and its impact on adenoma detection rate in screening colonoscopies. Ann Gastroenterol 2016; 29: 50 - 55

[20] Lee SW, Chang JH, Ji JS et al. Effect of dynamic position changes on adenoma detection during colonoscope withdrawal: a randomized controlled multicenter trial. Am J Gastroenterol 2016; 111: 63-69

[21] Chilton A, Rutter M , editors Quality Assurance Guidelines for Colonoscopy. NHS BCSP Publication No 6NHS Cancer Screening Programmes, Fulwood House; 2011: Available from: https://assets.publishing.service.gov.uk/government/uploads/system/uploads/attachment_data/file/427591/nhsbcsp06.pdf; Accessed 11 August 2018

[22] Gill MD, Bramble MG, Rees C] et al. Comparisons of screen-detected and interval colorectal cancers in the Bowel Cancer Screening Programme. Br J Cancer 2012; 107: 417-421

[23] Farrar WD, Sawhney MS, Nelson DB et al. Colorectal cancers found after complete colonoscopy. Clin Gastroenterol Hepatol 2006; 4: $1259-1264$

[24] Rex DK, Ponugoti PL. Calculating the adenoma detection rate in screening colonoscopies only: Is it necessary? Can it be gamed? Endoscopy 2017; 49: $1069-1074$ 